Editorial

\title{
VII Workshop on Lidar Measurements in Latin America (WLMLA)
}

\section{Taller de Medidas Lidar en Latinoamérica (WLMLA)}

Pucón, Chile, 11 a 16 de noviembre de 2013

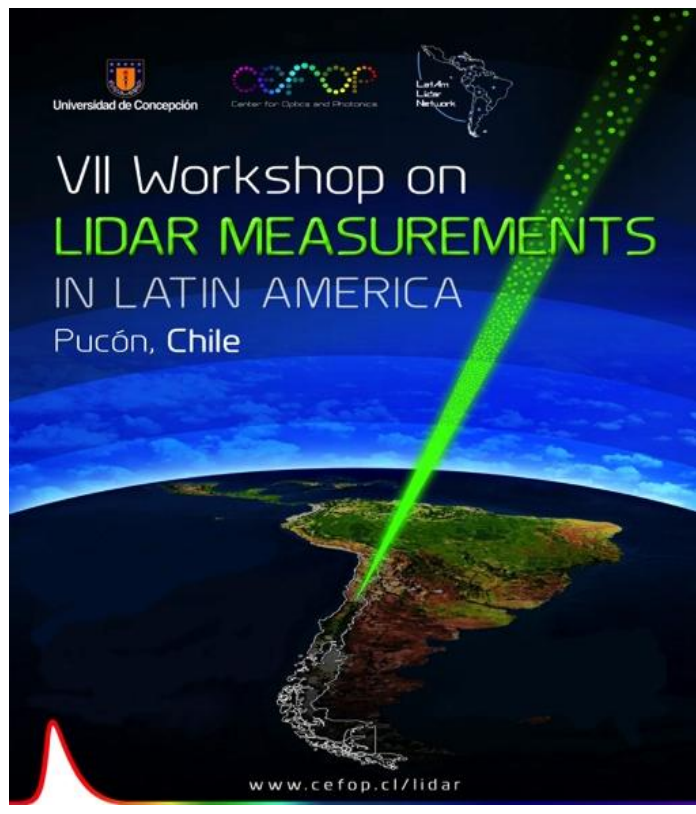

El Centro de Óptica y Fotónica (CEFOP) de la Universidad de Concepción, Chile, ha tenido el privilegio de realizar el VII Taller de Medidas Lidar en Latinoamérica (VII WLMLA), en la ciudad de Pucón, entre los días 11 y 16 de Noviembre del pasado año, 2013. Como en las exitosas ediciones anteriores de los Talleres bianuales de la Red Latinoamericana de Lidar (ALINE-Lalinet), el VII WLMLA sirvió de marco para la consolidación de las actividades de intercambio científico entre los investigadores y estudiantes en el área de Lidar de América Latina, con destacados investigadores reconocidos mundialmente. Así, de un total de 46 participantes, 35 provenían de los grupos de investigación en ciencias atmosféricas existentes en Argentina, Brasil, Bolivia, Chile, Colombia y Cuba, y 11, de los países invitados, España, Alemania, Italia, Holanda, Estados Unidos, México, Israel y Francia.
En el VII WLMLA, como continuación del formato utilizado en la versión anterior de La Paz, Bolivia, 2011, se incluyó la realización de la segunda escuela básica sobre técnicas Lidar durante los primeros tres días de la semana. En esta actividad, reconocidos científicos como el Dr. Albert Ansmann, Dr. Lucas Alados, Dr. Massimo Del Guasta y la Dra. Victoria Cachorro desde Europa, y el Dr. Eduardo Landulfo, Dr. Álvaro Bastidas y el Dr. René Estevan desde Latinoamérica, presentaron conferencias plenarias abarcando tópicos desde los fundamentos teóricos de la óptica atmosférica y la interacción radiación-materia, hasta las más recientes aplicaciones prácticas de la tecnología Lidar.

Durante el taller, se presentaron trabajos de investigación tanto en formato oral como poster, dentro de las líneas de interés de la red ALINELalinet: Metodología y tecnología Lidar, Sinergia 


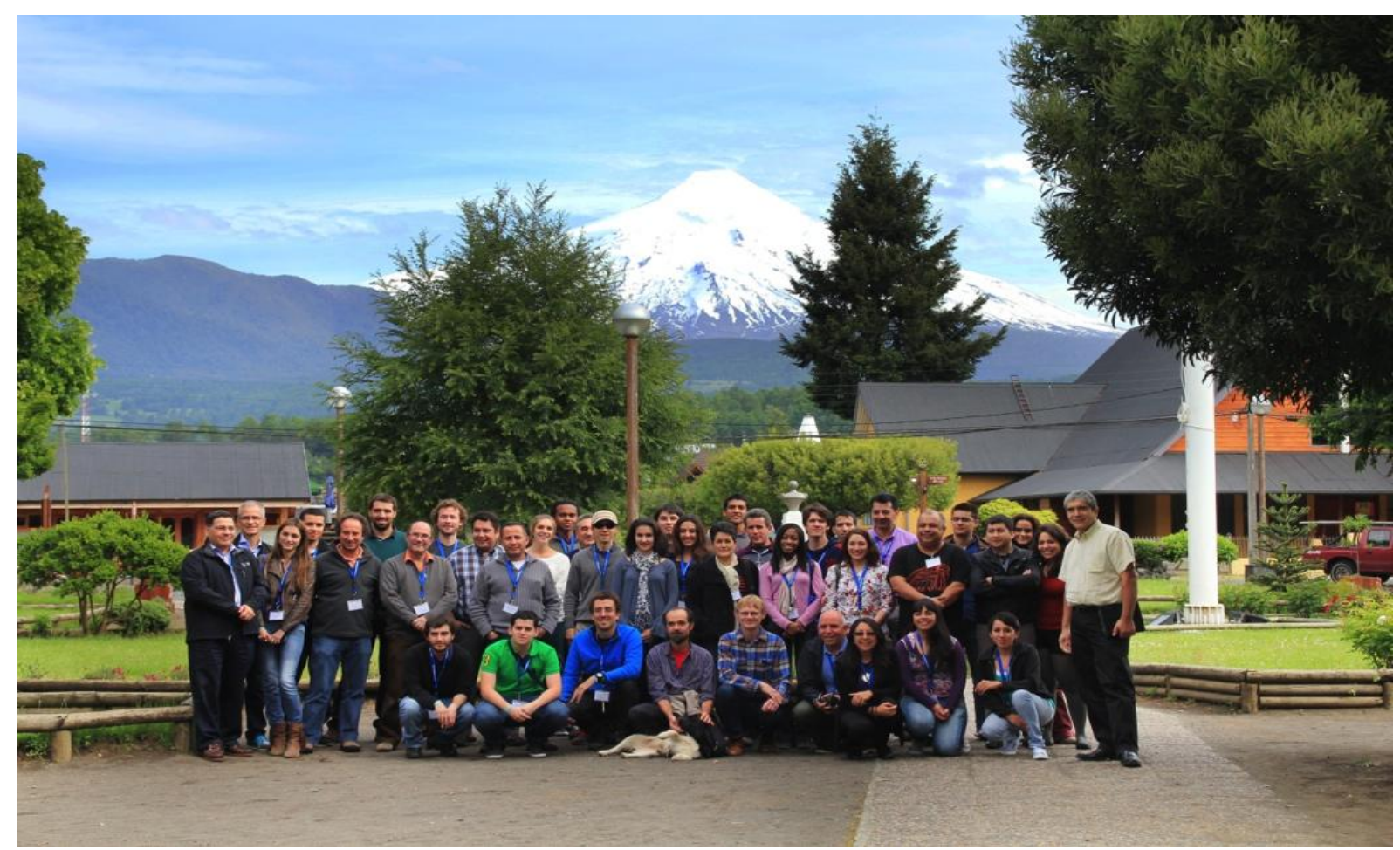

Fig. 1. Fotografía del los asistentes al VII WLMLA.

entre los sistemas Lidar e instrumentos complementarios, Redes Lidar, Aplicaciones de los sistemas Lidar en ciencias medioambientales, Aplicaciones de la detección remota y la Cooperación regional e internacional en tecnología Lidar. El 43\% del total de los trabajos aceptados en el taller fueron presentados por estudiantes y jóvenes investigadores, siendo éste un claro indicio de la garantía de continuidad en el desarrollo y establecimiento de la tecnología Lidar y sus aplicaciones en Latinoamérica.

La excelente asistencia y participación de los estudiantes, jóvenes investigadores e investigadores sénior que materializan los planes de colaboración e intercambio científico entre los miembros y colaboradores internacionales de la red ALINE-Lalinet, ha sido en gran parte posible gracias al apoyo de las 12 instituciones tanto de investigación como comerciales, a quienes el comité organizador desea agradecer especialmente. Así como también, agradecer al Grupo de Óptica Atmosférica (GOA) de la Universidad de Valladolid (España) y a la Sociedad Española de Óptica - SEDOPTICA, quienes de manera decidida han apoyado la publicación que hoy se presenta.

Como se ha determinado en la reunión de la Red ALINE-Lalinet celebrada durante el VII WLMLA, las nuevas ediciones del Taller, VIII y IX serán celebradas en los años 2015 y 2017, en Cuba y Medellín (Colombia), respectivamente, y donde espero nos encontremos nuevamente.

Elena Montilla-Rosero

Presidenta Comité Organizador VII WLMLA

DOI: http://dx.doi.org/10.7149/OPA.47.2.i 